\title{
Relapsing vivax malaria cluster in Eritrean refugees, Israel, June 2010
}

E Kopel (eran.kopel@mail.huji.ac.il)1, E Schwartz², Z Amitai ${ }^{1}$, I Volovik $^{1}$

1. Tel Aviv District Health Office, Ministry of Health, Tel Aviv, Israel

2. Centre for Geographic Medicine and Tropical Diseases, Sheba Medical Centre, Tel Hashomer, Ramat Gan, Israel

Kopel E, Schwartz E, Amitai Z, Volovik I. Relapsing vivax malaria cluster in Eritrean refugees, Israel, June 2010. Euro Surveill. 2010;15(26):pii=19601. Available online: http://www.eurosurveillance.org/ViewArticle.aspx?Articleld=19601

Article published on 1 July 2010

We report on a cluster of relapsing vivax malaria among Eritrean refugees residing in Israel. Since the beginning of 2010, 15 cases have been identified. Five of the six patients who had complete medical and epidemiological histories, reported Sudan as the place of primary infection during their journey to Israel, and having had the first relapse in Israel, six months later (median). Suggested place of exposure is the region of the Eritrean refugee camps in Sudan.

\section{Introduction}

Malaria, once endemic in Israel, was eradicated almost 50 years ago, although its vectors, several malariatransmitting species of Anopheles mosquitoes, still exist in various parts of the country $[1,2]$. Every year between 60 and 100 imported cases of malaria are reported to the Ministry of Health. Most of these cases are travellers returning from endemic countries to Israel and only few of them are immigrants from SubSaharan Africa [3].

Currently, there is a cluster of relapsing Plasmodium vivax malaria among Eritrean refugees in Israel. The epidemiological investigation, which is summarised here, was conducted by the local health office in Tel Aviv and is therefore limited to the Tel Aviv district.

\section{Methods}

On 7 June 2010, a cluster of five malaria cases was reported to the Tel Aviv District Health Office. These cases were Eritrean refugees under treatment in the same hospital during the first week of June. An epidemiological investigation was initiated. The case definition was laboratory-confirmed malaria excluding returning travellers.

The following investigation measures were taken.

- $\quad$ Species were identified by thick and thin smears with confirmation by real-time reverse-transcriptase PCR [4].

- Medical records of cases were obtained from hospitals.

- Oral interviews were conducted with four cases by a native speaker of Tigrinya (one of the two working languages in Eritrea). The interviews were based on a short epidemiological questionnaire that contained questions on demographics, the route of the journey to Israel, current and past malaria illness history and possible exposures (time, place, mosquito bites) in Israel or abroad.

- The local health office provided records on past epidemiological data regarding non-traveller cases of malaria in the district since 2006.

- An alert was issued to the hospitals and laboratories in the district, which were requested to report all cases of diagnosed malaria and to confirm them at the national reference laboratory.

- With the assistance of an expert malaria advisor, concise clinical guidelines for proper management $[5,6]$ of cases were promptly issued to local infectious diseases units at all hospitals in the district.

\section{Results}

Five cases of non-traveller malaria were reported in the district from 2006 to 2009 (Figure). All of these cases had been imported, three of whom were refugees from Eritrea. Since the beginning of 2010, 15 cases, all of them Eritrean refugees, have been reported. Most of them (nine of 15) were diagnosed in the first two weeks of June 2010. No other cases of imported malaria in other migrants were documented during this period of 2010 in the district.

Twelve cases were male ( $80 \%)$ and the median age was 25 years (interquartile range (IQR): 21.5-29 years). All the cases had laboratory-confirmed $P$. vivax infection. Low parasitaemia, ranging from $<0.1 \%$ to $1 \%$ at the time of diagnosis, was demonstrated for 12 patients for whom these data were known.

All 15 patients presented with similar clinical characteristics of intermittent fever which was usually accompanied by shivering and headaches. Eleven patients had mild to moderate anaemia, usually normocytic, and four of 15 patients had splenomegaly.

Thirteen of the 15 cases for whom the onset of illness and date of arrival to Israel were known had arrived in Israel during the six months before that date 
(median: 2.8 months, IQR: 0.7-4.4 months). Ten of the 15 cases had information on previous malaria attacks and reported having had one during the journey to Israel. For six of these 10 it was known that this previous attack occurred in Sudan, within the two-month period before arriving in Israel, of whom five recalled it was the primary infection. A further patient of these 10 reported a one-month period between the previous attack on the journey and arrival to Israel and another patient had the previous attack in Ethiopia, 12 months before arrival to Israel. An additional of the 15 patients, a 2.5-year-old female baby, had the first attack in Israel, approximately one month after her arrival through Sudan. No data on any previous attacks and their location were available for the last four of the 15 patients.

The median time interval between attacks was 6.1 months (IQR: 4.0-8.1 months, $n=9$ ). Five cases had received partial, inadequate or no treatment at the time of their previous attack, whereas no complete past medical history was available for the rest of the 15 patients.

The probable place of exposure of four patients who have been interviewed to date, was a complex with three refugee camps in Shagrab, operated by the United Nations' Refugee Agency, in southeastern Sudan, near the Eritrean border. In addition, the reported duration of stay in these camps was between one and two months before continuing directly to the Israeli border, by organised smuggling [7], apparently without significant stations of stay in neighbouring Egypt.

\section{Discussion}

We describe a cluster of relapsing vivax malaria among Eritrean refugees who had recently arrived in Israel. The fact that this cluster is mostly limited to young men probably reflects the overall current composition of Eritrean refugee population arriving in Israel. During the last several years until the end of 2009 , 9,517 Eritrean refugees, who constituted $48.6 \%$ of all asylum seekers, entered Israel. Since 2009, the

\section{FIGURE}

Laboratory-confirmed malaria cases (excluding returning travellers), Tel Aviv, Israel, 1 January 2006-15 June 2010 $(\mathrm{n}=18)$

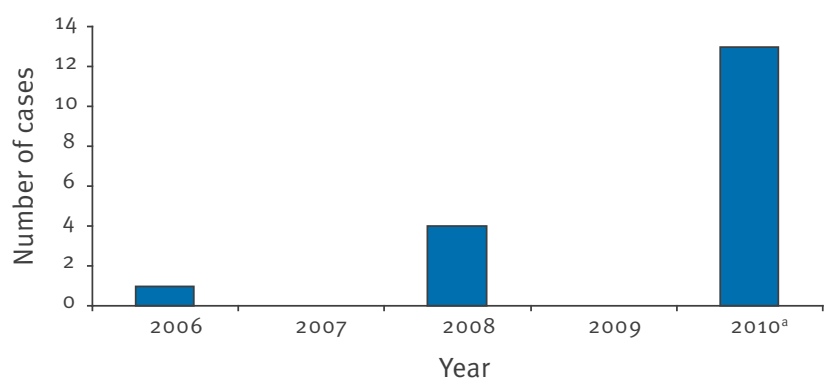

Number of cases until 15 June 2010. Two additional cases registered outside the district of Tel Aviv are not shown in the figure.
Eritrean refugees have gradually become the predominant group of asylum seekers who enter Israel from the Sinai desert (Egypt). In the first four months of 2010, 3,793 Eritrean refugees entered the country and constitute $82 \%$ of all asylum seekers who entered in this period [8].

These figures represent a $40 \%$ increase in the Eritrean refugee population in Israel during the first four months of 2010 alone. In addition, a more than fourfold increase in the crude incidence rate of non-traveller malaria in Israel was observed in the same period: in 2009, the crude incidence rate was 0.77 cases per 1,000 migrants, while in the first half of 2010 , it was 3.58 cases per 1,000 migrants*. These estimated calculations are based on data from the National Department of Epidemiology in the Israeli Ministry of Health and from an analysis report of the Knesset Research and Information Centre [8]. Consequently, an overall increase in malaria activity along the refugee route in Africa must have played a significant role in this cluster.

Therefore, it is reasonable to assume that a place on the journey is a recent common place of exposure. This place was most probably in Sudan rather than Eritrea as the lowland of Eritrea is mostly affected by $P$. falciparum and not by $P$. vivax [9]. Furthermore, a dramatic decline in the incidence rate of malaria was observed in the recent years in Eritrea, due to successful eradication programmes [10]. In fact, almost all cases who had complete medical and epidemiological history, namely a third of the total number of cases, specifically recalled having had the first malaria attack during their stay in Sudan, which was usually a period of two months before arriving to Israel.

Moreover, this cluster may actually reflect the expanding prevalence of a previously reported [11] small focus of vivax malaria in Sudan: 10 of 83 blood samples were PCR-positive for $P$. vivax (on the background of predominant $P$. falciparum in this area) in some of the Eritrean refugee camps in eastern Sudan, a frequently flooded low plain region in which malaria may have remained the leading cause of morbidity and mortality.

\section{Conclusions}

The evident ongoing rise of human reservoirs of malaria in the region may potentiate the risk for the re-emergence of locally acquired mosquito-transmitted malaria in Israel and neighbouring countries. This warrants tight national surveillance for new cases, proper clinical management and follow-up of current cases, and effective control measures of the local Anopheles vectors. In addition, it highlights the need for increased malaria surveillance in the refugee camps of eastern Sudan. 


\section{Acknowledgements}

We thank Anat Scheffer, Sofia Katser and Sara Germay for their assistance in the epidemiological investigation. We also thank the epidemiology unit of Tel Aviv Sourasky Medical Centre for the initial notification and the National Reference Centre for Parasitology for the cooperation.

*Authors'correction

The following correction was made on 5 July 2010 on request of the authors: In the Discussion section, the second sentence of the second paragraph: 'in 2009, the crude incidence rate was 0.77 per 1,000 cases, while in the first half of 2010 , it was 3.58 per 1,000 cases.' was replaced with the following sentence: 'in 2009, the crude incidence rate was 0.77 cases per 1,000 migrants, while in the first half of 2010 , it was 3.58 cases per 1,000 migrants.'

\section{References}

1. Pener H, Kitron U. Distribution of mosquitoes (Diptera: Culicidae) in northern Israel: a historical perspective. I. Anopheline mosquitoes. J Med Entomol. 1985;22(5):536-3.

2. Kitron U, Pener H, Costin C, Orshan L, Greenberg Z, Shalom U. Geographic information system in malaria surveillance: mosquito breeding and imported cases in Israel, 1992. Am J Trop Med Hyg. 1994;50(5):550-6.

3. Anis E, Pener H, Goldmann D, Leventhal A. [The reemergence of malaria in Israel?]. Harefuah. 2004;143(11):815-19, 838, 837. [Article in Hebrew].

4. Shokoples SE, Ndao M, Kowalewska-Grochowska K, Yanow SK. Multiplexed real-time PCR assay for discrimination of Plasmodium species with improved sensitivity for mixed infections. J Clin Microbiol. 2009;47(4):975-80.

5. Schwartz E, Regev-Yochay G, Kurnik D. Short report: a consideration of primaquine dose adjustment for radical cure of Plasmodium vivax malaria. Am J Trop Med Hyg. 2000;62(3):393-5.

6. Hill DR, Baird JK, Parise ME, Lewis LS, Ryan ET, Magill AJ. Primaquine: report from CDC expert meeting on malaria chemoprophylaxis I. Am J Trop Med Hyg. 2006;75(3):402-15.

7. Hartman B. UNHCR: Eritreans by far largest refugee group in Israel. Jerusalem Post. 10 March 2010. Available from: http:// www.jpost.com/Israel/Article.aspx?id=170593.

8. The Knesset Research and Information Center. [The management of infiltrators from the Egyptian border]. 26 May 2010. Available from: http://www.knesset.gov.il/mmm/data/ pdf/mo2524.pdf. [In Hebrew].

9. Sintasath DM, Ghebremeskel T, Lynch M, Kleinau E, Bretas G, Shililu J, et al. Malaria prevalence and associated risk factors in Eritrea. Am J Trop Med Hyg. 2005;72(6):682-7.

10. Nyarango PM, Gebremeskel T, Mebrahtu G, Mufunda J, Abdulmumini $U$, Ogbamariam A, et al. A steep decline of malaria morbidity and mortality trends in Eritrea between 2000 and 2004: the effect of combination of control methods. Malar J. 2006;5:33.

11. Charlwood JD, Qassim M, Elnsur El, Donnelly M, Petrarca V, Billingsley PF, et al. The impact of indoor residual spraying with malathion on malaria in refugee camps in eastern Sudan. Acta Trop. 2001;80(1):1-8. 